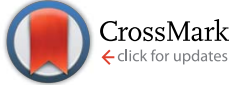

Cite this: RSC Adv., 2015, 5, 70743

Received 2nd August 2015 Accepted 7th August 2015

DOI: $10.1039 / \mathrm{c} 5 \mathrm{ra} 15394 \mathrm{~h}$

www.rsc.org/advances

\section{Amorphous carbon modified nano-sized tungsten carbide as a gas diffusion electrode catalyst for the oxygen reduction reaction}

\begin{abstract}
Zhiwei Liu, ${ }^{a}$ Ping Li, ${ }^{* a}$ Fuqiang Zhai, ${ }^{b}$ Qi Wan, ${ }^{c}$ Alex A. Volinsky ${ }^{d}$ and Xuanhui Qu$^{a}$
Nanostructured tungsten carbide with high surface area and containing amorphous carbon is prepared by a low temperature combustion synthesis method. The nanostructured tungsten carbide is used as the catalyst in a gas diffusion electrode. The obtained WC with different carbon content was investigated by XRD, FESEM, TG-DTA, BET and XPS. When the molar ratio of C/W is 19/3, the WC particles with different carbon content are obtained after a carbonizing process between 900 and $1400{ }^{\circ} \mathrm{C}$, and the content of free carbon in WC also increases gradually with temperature. The carbon content is tested by the high frequency combustion-infrared absorption method in a carbon sulfur analyzer. The electrochemical properties of the tungsten carbide for the oxygen reduction reaction are characterized by its polarization curves and electrochemical impedance. The results show that the presence of the appropriate amorphous carbon is beneficial for improving the conductivity and dispersibility of the tungsten carbide catalyst, and more active centers can be provided by the catalyst.
\end{abstract}

\section{Introduction}

Metal-air batteries have aroused great interest due to their simple structure, non-polluting and high power properties, and energy density. The cathodic oxygen reduction reaction (ORR) is one of the most important factors affecting the performance of a metal-air battery system. Among the cathode catalysts for metal-air batteries, platinum is currently the most used electrocatalyst for the ORR, ${ }^{1-3}$ owing to its high chemical stability and electro-catalytic activity. Meanwhile, the disadvantages of high cost and easy poisoning by carbon monoxide ${ }^{4}$ or methanol have greatly hindered the practical applications of metal-air batteries. At present, searching for other novel substitutes which could further improve the catalytic properties of oxygen electrodes has become a focal point of study in metal-air cells and fuel cells.

Nano-sized tungsten carbide (WC) is a new promising platinum-like catalyst for gas diffusion electrodes, not only due to its catalytic behavior, which is close to that of platinum, but also its electrochemical stability, oxidation resistance and antipoisoning are much higher than those of platinum catalysts. ${ }^{5-8}$

anstitute for Advanced Materials and Technology, University of Science and Technology Beijing, Beijing 100083, China. E-mail: ustbliping@126.com; Fax: +8610-62334311; Tel: $+86-10-82377286$

${ }^{b}$ Departament Física Aplicada, EETAC, Universitat Politècnica de Catalunya BarcelonaTech, 08860 Castelldefels, Spain

${ }^{c}$ Energy Material \& Technology Research Institute, General Research Institute for Nonferrous Metal, Beijing 100088, China

${ }^{d}$ Department of Mechanical Engineering, University of South Florida, Tampa, FL 33620, USA
Chen et al. ${ }^{9}$ reported that WC is active to methanol oxidation and is a promising alternative electrocatalyst at voltages up to $\sim 0.8 \mathrm{~V}$, WC also shows a high potential for the ORR due to its unique electronic structure. Due to a good electronic conductivity, WC will become an excellent material for diffusion barrier layers in the field of semiconductors. Besides, WC can be used as a support material for platinum catalysts, ${ }^{10}$ and the catalytic activity is also increased.

The presence of carbon on the WC surface has become a critical issue for the use of WC catalysts in electrochemical applications. The surface carbon will be present, unless properly controlled during the WC synthesis process, since the carbon source is derived from the decomposition of hydrocarbons. ${ }^{1122}$ The influence of the gas phase composition and synthesis temperature on the phases of $\mathrm{W}, \mathrm{W}$ carbides and $\mathrm{W}$ oxides with and without surface carbon have been reported. ${ }^{\mathbf{1 3 , 1 4}}$ Hara et $a l .{ }^{15}$ reported that the catalyst showed poor catalytic activity for hydrogen oxidation reactions (HORs) due to surface carbon. In the study of ordered macroporous tungsten carbide, Bosco et al. ${ }^{16}$ showed that surface carbon can stabilize the surface structure of WC, so the activity of methanol oxidation will be improved. In addition, Pt supported on mesoporous WC showed a better catalytic performance for hydrogen evolution reactions (HERs) ${ }^{\mathbf{1 7}}$ and methanol electro-oxidation ${ }^{\mathbf{1 8}}$ than $\mathrm{Pt}$ supported on carbon, which is due to the free carbon present on the surface of WC.

In this work, a WC precursor with a C/W molar ratio of 19/3 possessing higher catalytic properties was prepared by the low temperature combustion synthesis (LCS) method. The WC nanoparticles were obtained after carbonization of the 
precursor. The influence of different carbonization temperatures on the carbon content of the WC was studied. The electrochemical properties of the nano-sized WC with different surface amorphous carbon content were characterized by polarization curves and electrochemical impedance measurements.

\section{Experimental details}

\subsection{Preparation of the WC catalyst}

Mesoporous WC was synthesized by the LCS method, which is reported in a previous work. ${ }^{19}$ Ammonium tungstate $\left(\left(\mathrm{NH}_{4}\right)_{10} \mathrm{~W}_{12} \mathrm{O}_{41}\right)$, nitric acid $\left(\mathrm{HNO}_{3}, 65 \mathrm{wt} \%\right)$, urea $\left(\mathrm{CO}\left(\mathrm{NH}_{2}\right)_{2}\right)$ and glucose $\left(\mathrm{C}_{6} \mathrm{H}_{12} \mathrm{O}_{6} \cdot \mathrm{H}_{2} \mathrm{O}\right)$ were used as raw materials in the synthesis of the WC particles. First, $22.82 \mathrm{~g}$ of $\left(\mathrm{NH}_{4}\right)_{10} \mathrm{~W}_{12} \mathrm{O}_{41}, 3$ $\mathrm{g}$ of $\mathrm{CO}\left(\mathrm{NH}_{2}\right)_{2}$ and $18.81 \mathrm{~g}$ of $\mathrm{C}_{6} \mathrm{H}_{12} \mathrm{O}_{6} \cdot \mathrm{H}_{2} \mathrm{O}$ were dissolved together in $50 \mathrm{ml}$ of deionized water under stirring to obtain a redox mixture. Then, $9.69 \mathrm{~g}$ of $\mathrm{HNO}_{3}$ was added to the solution which was concentrated in a $500 \mathrm{ml}$ beaker. The mixed solution was placed into a closed electric furnace in order to initiate a highly exothermic self-contained combustion process, resulting in the production of a loose black WC precursor. Finally, the precursor was transferred into a tube furnace after grinding, where it was further carburized under an argon flow in the $800{ }^{\circ} \mathrm{C}$ to $1400{ }^{\circ} \mathrm{C}$ temperature range for $6 \mathrm{~h}$ to obtain the samples. In order to conveniently describe the products of pure, reduced and carburized WCs at different temperatures, hereafter, these products are named as catalyst A, B, C, D or E, corresponding to the reduction and carburization at $900{ }^{\circ} \mathrm{C}$, $1000{ }^{\circ} \mathrm{C}, 1100{ }^{\circ} \mathrm{C}, 1200{ }^{\circ} \mathrm{C}$ or $1400{ }^{\circ} \mathrm{C}$, respectively.

\subsection{Sample characterization}

The X-ray diffraction (XRD) measurements were carried out on a Rigaku (D/MAX-RB) diffractometer using $\mathrm{Cu} \mathrm{K} \alpha$ radiation $(\lambda=$ $1.5406 \AA$ ) at a scanning rate of $10^{\circ} \mathrm{min}^{-1}$. The morphology and nanostructure of the samples were observed using a fieldemission scanning electron microscope (FESEM, Zeiss Ultra 55). The thermal stability of the samples was studied by TG-DTA (Seiko 6300) and the data were recorded from room temperature to $1000{ }^{\circ} \mathrm{C}$ at a heating rate of $10{ }^{\circ} \mathrm{C} \mathrm{min}^{-1}$ under air atmosphere. The BET (QuadraSorb SI) surface area measurement was calculated from the nitrogen adsorption isotherms at $-196{ }^{\circ} \mathrm{C}$. The content of the carbon element was measured using an infrared absorption carbon-sulfur analyzer (CS-2008). The energy dispersive X-ray spectra (EDS) attached to the FESEM and X-ray photoelectron spectroscopy (XPS, ESCALAB $250 \mathrm{Xi}$ ) were also used to investigate the near surface chemical composition of the samples.

\subsection{Gas diffusion electrode preparation}

The gas diffusion electrodes were prepared according to earlier reports, ${ }^{20,21}$ and consist of three layers: a catalyst layer, a gas diffusion layer and a current collecting layer. The preparation process of the catalyst layer can be described as follows: tungsten carbide, acetylene black and polytetrafluoroethylene (PTFE, 60 wt\% suspension), according to a weight ratio of
$3: 5: 2$, were mixed in $20 \mathrm{ml}$ of deionized water, and the appropriate amount of anhydrous ethanol was added. The mixture became a tough and sticky paste under magnetic stirring at $80{ }^{\circ} \mathrm{C}$ for $2 \mathrm{~h}$. Under a pressure of $16 \mathrm{MPa}$, the paste was pressed into a size-specific catalyst layer by using a pellet press. A similar method was used to prepare the gas diffusion layer. The weight ratio of polytetrafluoroethylene to anhydrous sodium sulfate to acetylene black was $1: 1: 1$. In the process, PTFE, anhydrous sodium sulfate and acetylene black were used as the binder, the pore former and the support material, respectively. Nickel foam was chosen as the current collector in the moisture barrier. The gas diffusion electrodes were obtained by pressing the three layers together. Finally, the electrodes were finished by sintering at $200{ }^{\circ} \mathrm{C}$ in a nitrogen flow for 30 min. The loading amount of the active materials was $5 \mathrm{mg}$ $\mathrm{cm}^{-2}$. The Pt (10 wt\% Pt, Aladdin) gas diffusion electrode and activated carbon (AC) gas diffusion electrode were also prepared by following the same procedure as above.

\subsection{Electrochemical characterization}

Electrochemical measurements were carried out in a conventional three-electrode system using a Parstat 2273 electrochemical workstation at $30{ }^{\circ} \mathrm{C}$. Nickel foil was used as the counter electrode and the prepared gas diffusion electrode was used as the working electrode. The area of the working electrode is $0.785 \mathrm{~cm}^{2}$. Under alkaline conditions, the $\mathrm{Hg} / \mathrm{HgO}$ electrode was used as the reference electrode and the electrolyte was a $6 \mathrm{M}$ $\mathrm{KOH}$ solution. Under neutral $\mathrm{pH}$ conditions, a saturated calomel electrode (SCE) was used as the reference electrode and the electrolyte was a $1 \mathrm{M} \mathrm{NaCl}$ solution. The steady state polarization curve measurements were conducted with a scan rate of $0.5 \mathrm{mV} \mathrm{s}^{-1}$. The electrochemical impedance spectra (EIS) were recorded in the $0.01 \mathrm{~Hz}$ to $10 \mathrm{kHz}$ ac signal range with a 5 mV amplitude.

\section{Results and discussion}

\subsection{Characterization of the as-synthesized WC catalyst}

The precursor with the 19/3 C/W molar ratio was reduced and carburized at the different temperatures under argon atmosphere for $6 \mathrm{~h}$. The X-ray diffraction patterns of the different samples are shown in Fig. 1. Obvious WC peaks and $\mathrm{W}_{2} \mathrm{C}$ peaks appear when the temperature increases to $800{ }^{\circ} \mathrm{C}$, suggesting that the carbonization reaction of the precursors had occurred. When the reduction carbonization temperature is higher than $900{ }^{\circ} \mathrm{C}$, strong WC peaks can be observed in Fig. 1, indicating that $\mathrm{WO}_{3}$ completely transformed into pure WC through the carbonization process. According to the results calculated by the Scherrer formula, the average particle sizes of the catalysts are $50.0 \mathrm{~nm}, 46.8 \mathrm{~nm}, 39.1 \mathrm{~nm}, 57.3 \mathrm{~nm}$ and $59.0 \mathrm{~nm}$, which correspond to catalysts A, B, C, D and E, respectively. Therefore, the carburization temperature affects the final WC phase generation.

Fig. 2 displays the FESEM micrographs of the products prepared at different carbonization temperatures. The small amount of porosity appearing in the tungsten carbide samples 


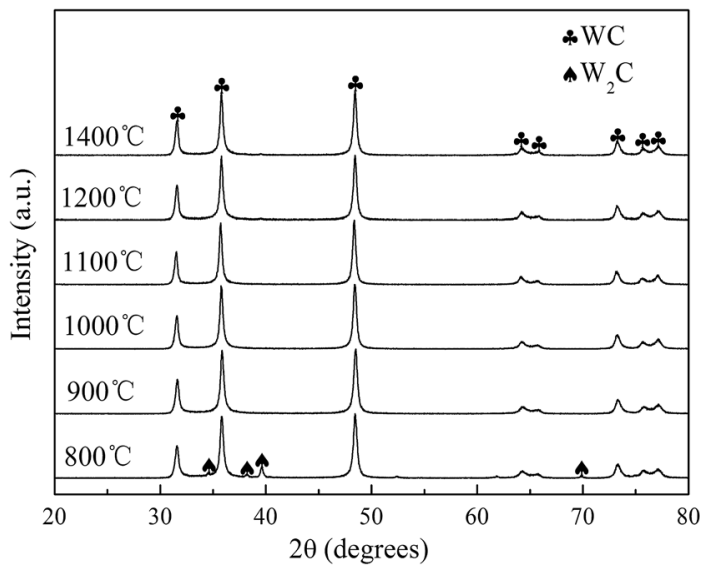

Fig. 1 X-ray diffraction patterns of the tungsten carbide synthesized at different carbonization temperatures.

results from a large amount of released heat during the low temperature combustion process. As shown in Fig. $2 \mathrm{a}-\mathrm{c}$, the particle size of the samples decreases with the rise in temperature. The particle size of the catalyst lies within a wide range, and agglomeration will happen during carbonization. When the carbonization temperature reaches $1100{ }^{\circ} \mathrm{C}$, a small sized catalyst (C) can be obtained with homogeneous nano-sized particles of 40-50 nm. At this temperature, the morphology of the WC particles has been transformed from irregular to spherical, and catalyst $\mathrm{C}$ has the highest specific surface area. With further increase in the carbonization temperature, the tendency of the powder to agglomerate becomes more obvious and the particle size also tends to increase. The particle sizes of
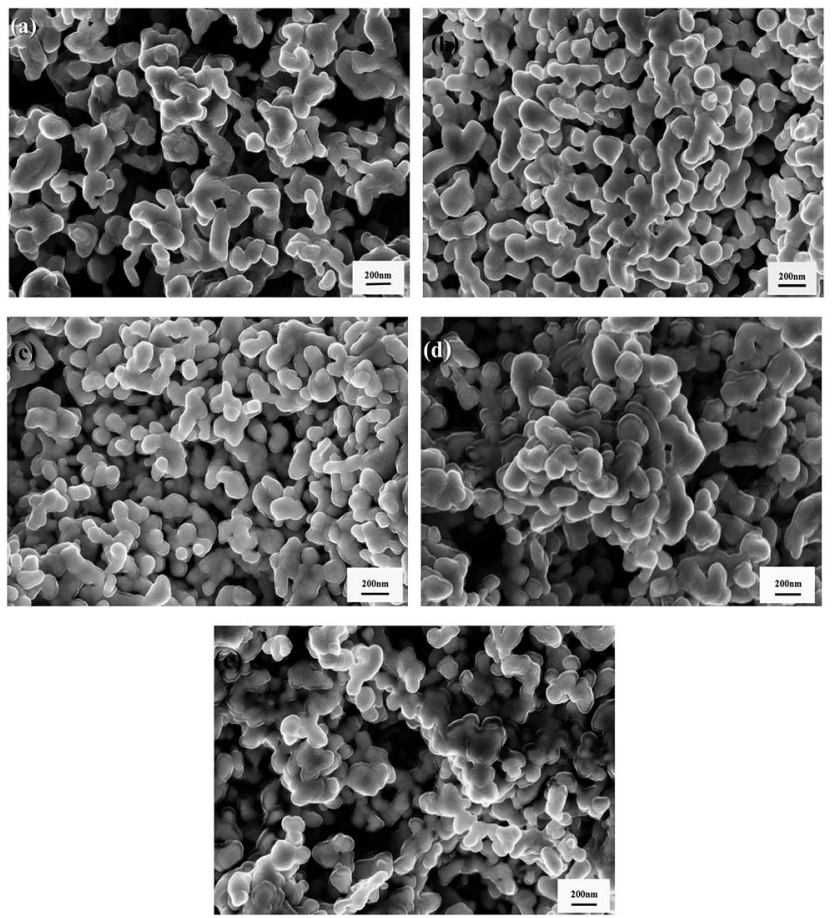

Fig. 2 FESEM micrographs of the products of WC: (a) catalyst A; (b) catalyst B; (c) catalyst $C$; (d) catalyst D and (e) catalyst E. catalyst D and catalyst $\mathrm{E}$ are both larger than that of catalyst C, which is consistent with the XRD results.

The $\mathrm{N}_{2}$ adsorption/desorption isothermal curves of catalyst $\mathrm{C}$ are shown in Fig. 3. The sample exhibited the representative type IV isotherms with a distinct hysteresis loop over the $P / P_{0}$ ranging from 0.42 to 0.98 , clearly showing the mesoporous properties of the prepared WC. In addition, the pore size distribution is shown in the inset of Fig. 3, demonstrating that catalyst $\mathrm{C}$ is mesoporous with a maximum diameter of $3.84 \mathrm{~nm}$. Based on the above analysis, it is reasonable to believe that the mesoporous structure of WC is suitable to allow its use as an electrochemical catalyst material.

The specific surface area and the carbon content of the tested samples have been obtained, as shown in Table 1. The carbon content of all the samples is higher than the theoretical carbon content $(\mathrm{C} / \mathrm{WC}=6.12 \mathrm{wt} \%)$, suggesting the inevitable existence of free carbon in the final product; the free carbon content increases with the increase of the carbonization temperature. The specific surface area of catalyst B is slightly higher than that of catalyst A due to the smaller particle size of catalyst $B$. The surface profile changes when the carbonization temperature is higher than $1000{ }^{\circ} \mathrm{C}$. The specific surface area of WC shows a tendency to increase with increasing carbonization temperature. When the carbonization temperature increases to $1100{ }^{\circ} \mathrm{C}$, the specific surface area of the WC reaches $41.297 \mathrm{~m}^{2} \mathrm{~g}^{-1}$. However, with further increase in temperature, the specific surface area of the WC decreases, due to particle agglomeration.

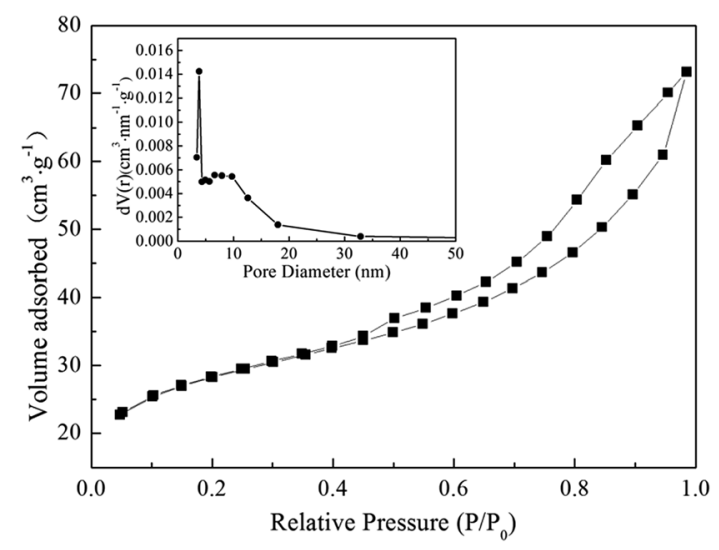

Fig. $3 \quad \mathrm{~N}_{2}$ adsorption-desorption isotherms of the catalyst $\mathrm{C}$ sample (inset: $\mathrm{BJH}$ pore size distribution).

Table 1 The BET and carbon content of the products

\begin{tabular}{llll}
\hline The products & $\begin{array}{l}\text { C wt\% } \\
\text { in the product }\end{array}$ & $\begin{array}{l}\text { Free carbon wt\% } \\
\text { in the product }\end{array}$ & BET $\left(\mathrm{m}^{2} \mathrm{~g}^{-1}\right)$ \\
\hline Catalyst A & 6.66 & 0.54 & 19.754 \\
Catalyst B & 6.70 & 0.58 & 24.342 \\
Catalyst C & 7.10 & 0.98 & 41.297 \\
Catalyst D & 8.62 & 2.50 & 36.612 \\
Catalyst E & 8.66 & 2.54 & 31.295
\end{tabular}


Fig. 4 shows the thermogravimetry-differential thermal analysis (TG-DTA) of catalyst $\mathrm{C}$ measured under air atmosphere. The TG curve of catalyst $\mathrm{C}$ shows a significant increase at $425^{\circ} \mathrm{C}$, which indicates that the weight of the sample has increased. The weight of catalyst $\mathrm{C}$ remains stable above $670{ }^{\circ} \mathrm{C}$. The DTA curve shows that the exothermic reaction occurs between $425^{\circ} \mathrm{C}$ and $670{ }^{\circ} \mathrm{C}$ for catalyst $\mathrm{C}$. The results show that the WC sample prepared by the low-temperature combustion synthesis method is stable under temperatures below $425{ }^{\circ} \mathrm{C}$. When the temperature is higher than $425{ }^{\circ} \mathrm{C}$, the WC sample reacts with oxygen to produce tungsten oxide, and apparent heat is given off. It is consistent with the results in the literature..$^{22}$

Fig. 5 shows the XPS spectra for the surface composition of catalyst A. As shown in Fig. 5a, the spectrum of $\mathrm{C} 1 \mathrm{~s}$ for catalyst A consists of a doublet with $284.68 \mathrm{eV}$ and $282.7 \mathrm{eV}$ binding energies, corresponding to amorphous carbon and WC. Fig. 5b shows the XPS spectrum of $\mathrm{W}$ 4f with peaks at $32.1 \mathrm{eV}, 34.2 \mathrm{eV}$, and $38.1 \mathrm{eV}$, which are ascribed to $\mathrm{WC}, \mathrm{W}_{2} \mathrm{C}$, and $\mathrm{W}_{x} \mathrm{O}_{y}$, respectively. The existence of $\mathrm{W}_{x} \mathrm{O}_{y}$ shows that the exposed sample was oxidized in air. The elemental content of the different surface products was characterized by XPS, as shown in Table 2. All tungsten carbide surfaces prepared at different carbonization temperatures have a high oxygen content. The surface elemental content obviously changes with the carbonization temperature. With the rise in carbonization temperature, the surface carbon content increases, but the oxygen content decreases. After a carbon atom is replaced by an oxygen atom, tungsten oxide can stabilize the surface of tungsten carbide. The passive oxide films are formed on the surface of the pure WC, so the corrosion resistance of the WC is significantly increased. ${ }^{23}$

\subsection{Electrocatalytic activity of the different catalysts}

3.2.1 Polarization curves. Fig. 6 shows the linear polarization curves of the gas diffusion electrodes with the different catalysts. The polarization curves of the different electrodes are almost the same in the low potential area, indicating that the electrochemical performance of all catalysts is quite close, as

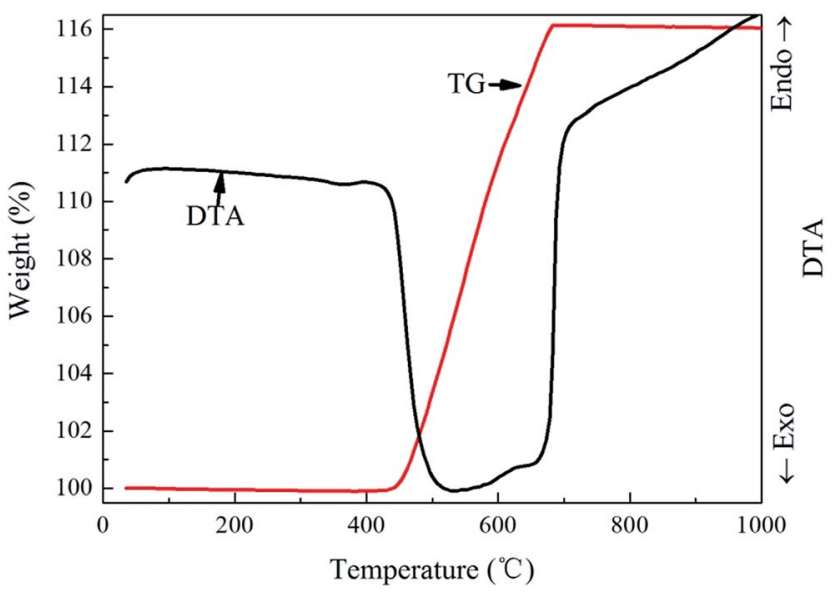

Fig. 4 DG-DTA curves of catalyst C.
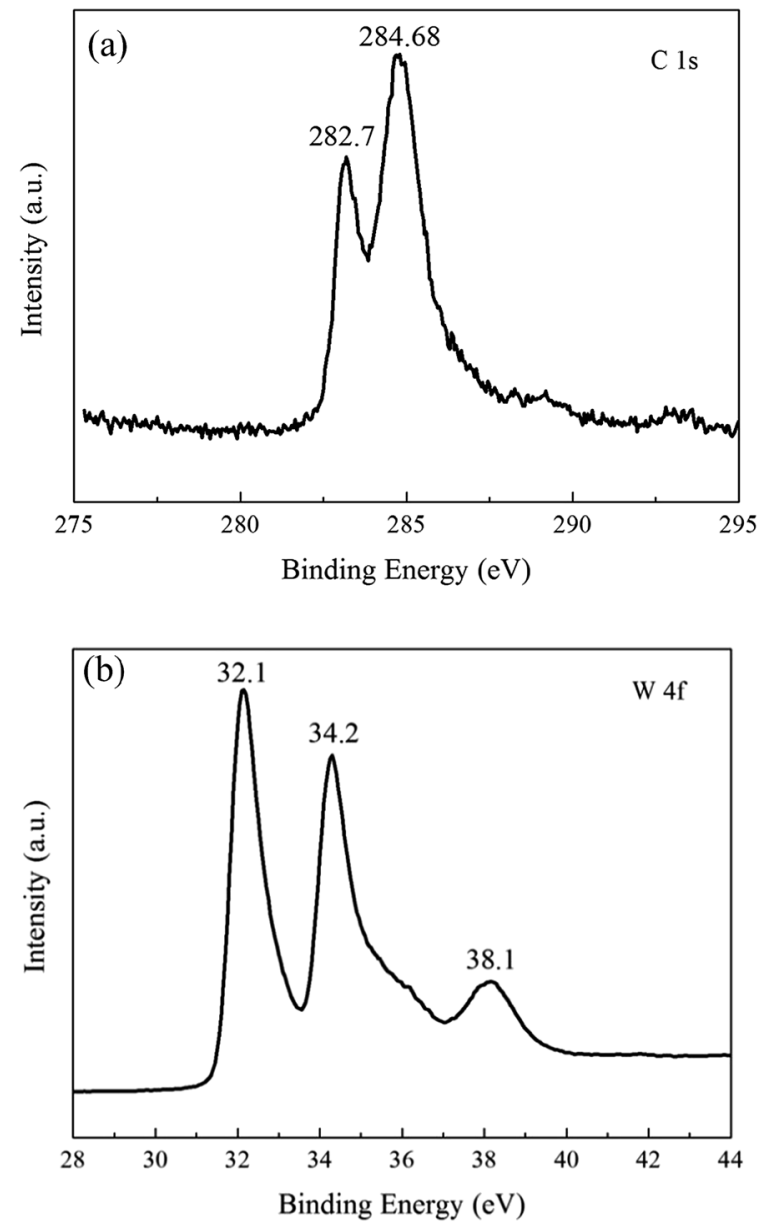

Fig. 5 XPS spectra of catalyst A: (a) C 1s peaks and (b) W 4 f peaks.

Table 2 The surface element content of the different products

\begin{tabular}{llll}
\hline & \multicolumn{3}{c}{ Atomic content (mole percentage, \%) } \\
\cline { 2 - 4 } The products & $\mathrm{C}$ & $\mathrm{W}$ & $\mathrm{O}$ \\
\hline Catalyst A & 38 & 34 & 28 \\
Catalyst B & 40 & 34 & 26 \\
Catalyst C & 48 & 35 & 17 \\
Catalyst D & 53 & 35 & 12 \\
Catalyst E & 55 & 35 & 10 \\
\hline
\end{tabular}

seen in Fig. 6a and b. However, the electrode polarization current density of catalyst $\mathrm{C}$ is higher than those of the other electrodes in the high potential area. Thus, it can be concluded that catalyst $\mathrm{C}$ has a higher catalytic performance. These results indicate that catalyst $\mathrm{C}$ is an active catalyst for the ORR in alkaline solutions. Due to the high specific surface area of all the samples and the presence of moderate free carbon, catalyst $\mathrm{C}$ has a more catalytic active center, which facilitates mass transportation and ensures the accessibility of the reactant molecules. ${ }^{24}$ The catalytic activity of catalyst $\mathrm{C}$ is the highest amongst all samples. Therefore, more amorphous carbon in the 

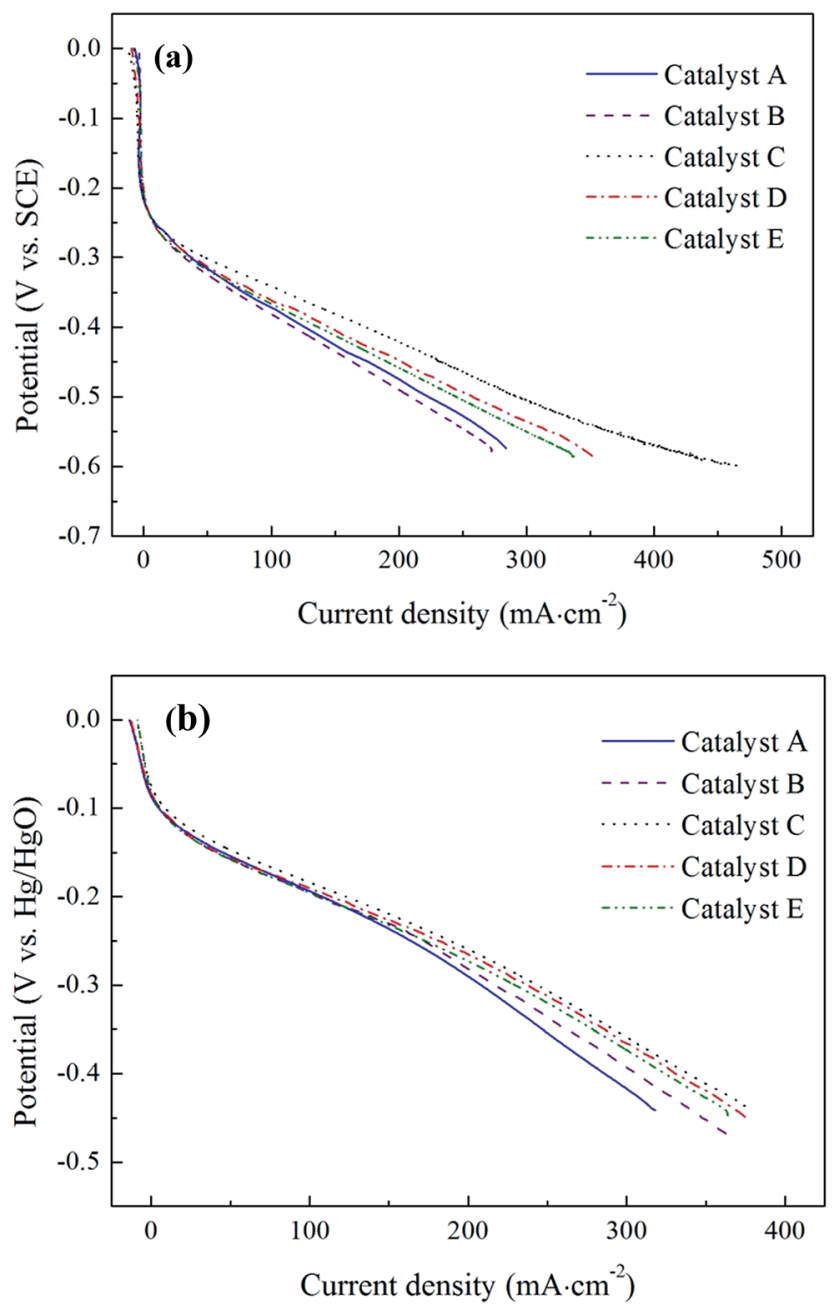

Fig. 6 Linear polarization curves of the gas diffusion electrodes with different catalysts (A-E): (a) neutral solution and (b) alkaline solution.

WC will lower the activity of the catalysts, ${ }^{25}$ as shown for catalyst $\mathrm{D}$ and catalyst $\mathrm{E}$.

To further investigate these electrochemical properties, activated carbon and Pt gas diffusion electrodes were used to compare their electrocatalytic activity with that of the prepared catalyst C. As shown in Fig. 7, the polarization measurements of all the gas diffusion electrodes show no obvious distinction between $-0.2 \mathrm{~V}$ and $0 \mathrm{~V}$. In the high potential area, the polarization current density with catalyst $\mathrm{C}$ is higher than those for the activated carbon and $\mathrm{Pt}$ gas diffusion electrodes. The current density of the catalyst $\mathrm{C}$ gas diffusion electrode at -0.45 $\mathrm{V}$ is $220 \mathrm{~mA} \mathrm{~cm}^{-2}$, which is a little higher than that of the Pt gas diffusion electrode with a current density of $209 \mathrm{~mA} \mathrm{~cm}^{-2}$. Considering the high price of Pt catalysts, it is reasonable to believe that the WC catalyst is a good alternative to the Pt catalyst.

3.2.2 Electrochemical impedance spectroscopy. Fig. 8 exhibits the EIS curves at $0.05 \mathrm{~V}$ ( $v s$. SCE) with a test frequency range between $0.01 \mathrm{~Hz}$ and $10 \mathrm{kHz}$. The semicircle impedances show that the ORR charge transfer resistance $\left(R_{\mathrm{ct}}\right)$ corresponds to the charge transfer step in neutral solution. It is clearly seen

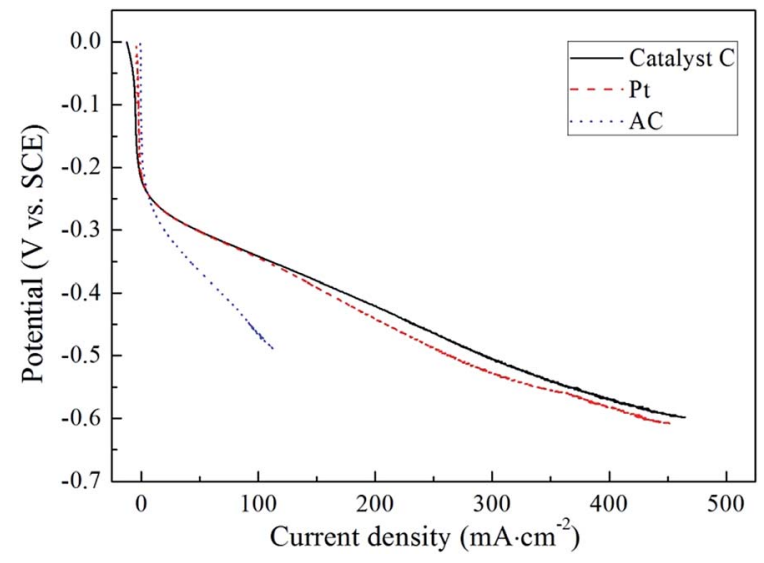

Fig. 7 Linear polarization curves of the gas diffusion electrodes with catalyst C, Pt and activated carbon in the neutral solution.

from Fig. 8a that the semicircle impedance of the catalyst $\mathrm{C}$ electrode is the smallest among all electrodes at the tested potential. Thus, it is reasonable to believe that catalyst $\mathrm{C}$ has a better catalytic activity than the other catalysts. Fig. 8b shows the corresponding Nyquist plots of the different electrodes in alkaline solution. All impedances of the electrodes present
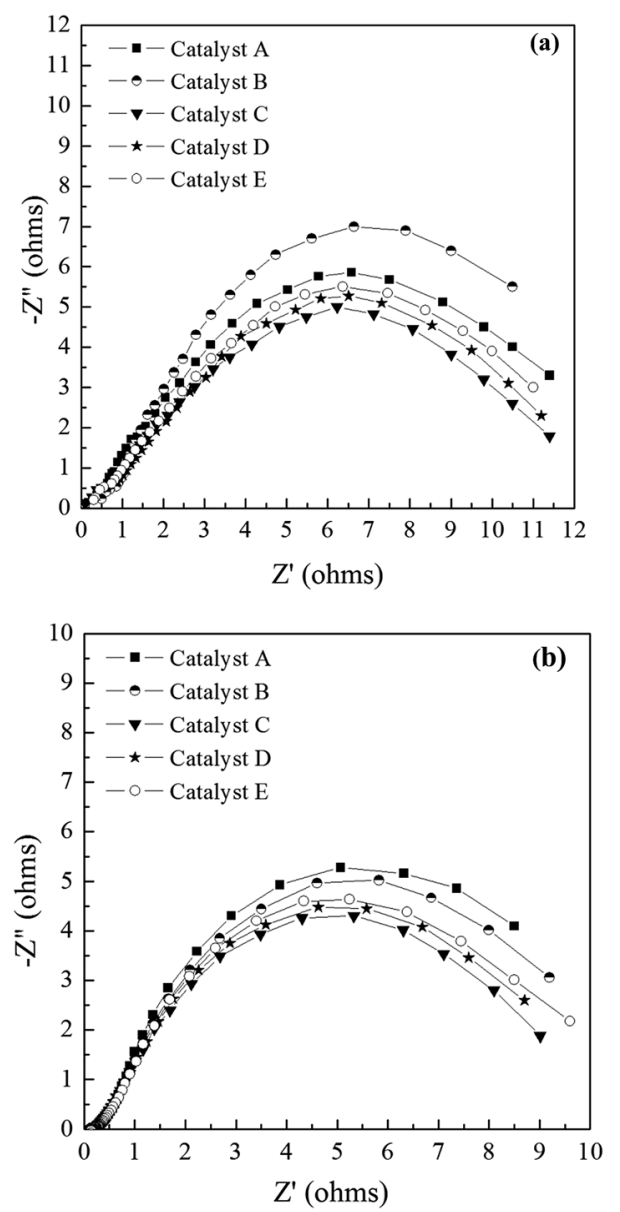

Fig. 8 Impedance spectra of the gas diffusion electrodes with different catalysts (A-E); (a) neutral solution and (b) alkaline solution. 
semicircles in the impedance test, which are similar to Fig. 8a. According to the size of the semicircle diameter, it can be concluded that ORR on the catalyst $\mathrm{C}$ electrode is more favorable. Catalyst $\mathrm{C}$ shows a better catalytic activity resulting from enhanced reaction kinetics. ${ }^{26}$ The results of the electrochemical impedance test show that the amorphous carbon content has an important effect on the catalytic activity of WC, which is consistent with the experimental polarization curves.

\section{Conclusions}

In summary, this work successfully prepared a mesoporous WC with a high catalytic activity and specific surface area by the low temperature combustion synthesis method. With increasing carbonization temperatures, the amorphous carbon content of the prepared WC increases. The presence of a moderate amount of oxygen is beneficial to improve the stability of the tungsten carbide. The as-prepared mesoporous WC nanoparticles exhibit excellent performances for the ORR, mainly due to the free carbon content and morphological characteristics of the mesoporous materials. This study clearly indicates that the amorphous carbon has an important effect on the catalytic activity of the WC catalysts.

\section{Acknowledgements}

Ping Li and Fuqiang Zhai thank the China Scholarship Council (CSC) for providing the scholarship.

\section{References}

1 H. Meng and P. K. Shen, Electrochem. Commun., 2006, 8, 588594.

2 H. Meng and P. K. Shen, Chem. Commun., 2005, 1, 44084410.

3 M. Nie, H. L. Tang, Z. D. Wei, S. P. Jiang and P. K. Shen, Electrochem. Commun., 2007, 9, 2375-2379.

4 G. J. K. Acres, J. C. Frost, G. A. Hards, R. J. Poter, T. R. Ralph, D. Thompsett, G. T. Burstein and G. J. Hutchings, Catal. Today, 1997, 38, 393-400.

5 R. B. Levy and M. Boudart, Science, 1973, 181, 547-549.

6 Z. J. Mellinger, T. G. Kelly and J. G. Chen, ACS Catal., 2012, 2, 751-758.
7 M. B. Zellner and J. G. Chen, J. Catal., 2005, 235, 393-402.

8 H. Chhina, S. Campbell and O. Kesler, J. Power Sources, 2007, 164, 431-440.

9 E. C. Weigert, A. L. Stottlemyer, M. B. Zellner and G. C. Jingguang, J. Phys. Chem. C, 2007, 111, 14617-14620.

10 Z. Zhao, X. Fang, Y. Li, Y. Wang, P. K. Shen, F. Xie and X. Zhang, Electrochem. Commun., 2009, 11, 290-293.

11 J. Lemaitre, B. Vidick and B. Delmon, J. Catal., 1986, 99, 415427.

12 B. Vidick, J. Lemaitre and B. Delmon, J. Catal., 1986, 99, 428438.

13 G. Leclercq, M. Kamal, J. F. Lamonier, L. Feigenbaum, P. Malfoy and L. Leclercq, Appl. Catal., A, 1995, 121, 169-190.

14 G. Leclercq, M. Kamal, J. M. Giraudon, P. Devassine, L. Feigenbaum, L. Leclercq, A. Frennetb, J. M. Bastinb, A. Löfbergb, S. Deckerb and M. Dufourb, J. Catal., 1996, 158, 142-169.

15 Y. Hara, N. Minami and H. Itagaki, Appl. Catal., A, 2007, 323, 86-93.

16 J. P. Bosco, K. Sasaki, M. Sadakane, W. Ueda and J. G. Chen, Chem. Mater., 2010, 22, 966-973.

17 D. J. Ham, R. Ganesan and J. S. Lee, Int. J. Hydrogen Energy, 2008, 33, 6865-6872.

18 Z. Fu, Q. M. Huang, X. D. Xiang, Y. L. Lin, W. Wu, S. J. Hu and W. S. Li, Int. J. Hydrogen Energy, 2012, 37, 4704-4709.

19 P. Li, Z. W. Liu, L. Q. Cui, F. Q. Zhai, Q. Wan, Z. L. Li, Z. Z. Fang, A. A. Volinsky and X. H. Qu, Int. J. Hydrogen Energy, 2014, 39, 10911-10920.

20 J. F. Drillet, H. Bueb, U. Dettlaff-Weglikowska, R. Dittmeyer and S. Roth, J. Power Sources, 2010, 195, 8084-8088.

21 C. Tran, X. Q. Yang and D. Qu, J. Power Sources, 2010, 195, 2057-2063.

22 C. A. Ma, W. M. Zhang, G. H. Li, Y. F. Zheng, B. X. Zhou and D. H. Cheng, Acta Chim. Sin., 2005, 63, 1151-1154.

23 K. C. Lee, A. Ishihara, S. Mitsushima, N. Kamiyaa and K. Ota, Electrochim. Acta, 2004, 49, 3479-3485.

24 H. Zheng, Z. Chen and Y. Li, Electrochim. Acta, 2013, 108, 486-490.

25 X. Yang, Y. C. Kimmel, J. Fu, B. E. Koel and J. G. Chen, ACS Catal., 2012, 2, 765-769.

26 E. H. Yu, K. Scott and R. W. Reeve, J. Electroanal. Chem., 2003, 547, 17-24. 